\title{
PRIMEIRA NOTIFICAÇÃO DE CASOS HUMANOS DE LEISHMANIOSE VISCERAL NO ANO DE 2014 EM TRÊS MUNICÍPIOS DO ESTADO DE SÃO PAULO
}

\author{
FIRST NOTIFICATION OF HUMAN CASES OF VISCERAL LEISHMANIASIS IN THE \\ YEAR 2014 IN THREE MUNICIPALITIES OF SÃO PAULO STATE
}

\author{
E. M. N. de PAULA ${ }^{1}$, N. C. MARQUES ${ }^{2}$, M. B. D. OLIVARI ${ }^{2}$, B. F. IZOLA², J. H. B. TOSCANO², \\ A. P. R. GRISÓLIO², R. B. MEIRELLES-BARTOLI ${ }^{1}$, A. A. B. CARVALHO²
}

\section{RESUMO}

A leishmaniose visceral é uma importante zoonose emergente, de origem parasitária, com distribuição mundial e ainda muito negligenciada. Esta enfermidade é causada por protozoários do gênero Leishmania que são intracelulares obrigatórios de células do sistema fagocítico mononuclear de hospedeiros vertebrados. Esta é uma doença relacionada principalmente à pobreza e a conflitos sociais, infectando milhares de pessoas no mundo todo, podendo variar os sintomas e manifestações clínicas. O objetivo deste trabalho foi descrever todos os municípios do Estado de São Paulo que notificaram pela primeira vez, no ano de 2014, casos humanos autóctones. Trata-se de um estudo descrito, utilizando-se dados referentes aos casos humanos autóctones de LLeishmaniose visceral obtidos juntos ao Centro de Vigilância Epidemiológica (CVE) e à Superintendência de Controle de Endemias (SUCEN) do Estado de São Paulo. Foram notificados casos humanos autóctones pela primeira vez no ano de 2014 nos municípios Marabá Paulista, Presidente Epitácio e Iacri. Nenhuma dessas cidades possui casos caninos. Todas possuem registro do vetor: Iacri (2004), Presidente (2009) e Marabá (2012). Segundo o Ministério da Saúde, essas três cidades são classificadas como municípios com transmissão humana, ou seja, municípios onde o ser humano é acometido pela doença. As investigações epidemiológicas são fundamentais na elaboração das estratégias públicas de combate e prevenção às patologias que acometem a sociedade. As estatísticas provenientes dessas investigações permitem identificar populações e fatores de risco precocemente e combatê-los de maneira mais efetiva através das medidas de controle e prevenção mais aplicáveis àquela situação.

PALAVRAS-CHAVE: ZOONOSE. LEISHMANIOSE VISCERAL AMERICANA. VIGILÂNCIA EPIDEMIOLÓGICA. NOTIFICAÇÃO.

AGRADECIMENTOS: Superintendência de Controle de Endemias (SUCEN) do Estado de São Paulo

ÁREA TEMÁTICA: 6. Zoonoses

\footnotetext{
${ }^{1}$ Universidade Federal de Goiás (UFG), Regional Jataí, Unidade Jatobá, Laboratório de Sanidade Animal

${ }^{2}$ Faculdade de Ciências Agrárias e Veterinárias da Universidade Estadual Paulista (UNESP) - Câmpus de Jaboticabal

* nat.cassaro@gmail.com
} 